\title{
Lusioersily
}

\section{Production and characterization of PEEK/IF-WS2 nanocomposites for Additive Manufacturing: simultaneous improvement in processing characteristics and material properties}

Golbang, A., Harkin-Jones, E., Wegrzyn, M., Campbell, G., Archer, E., \& Mcllhagger, AT. (2020). Production and characterization of PEEK/IF-WS2 nanocomposites for Additive Manufacturing: simultaneous improvement in processing characteristics and material properties. Additive Manufacturing, 31, 1-8. [100920].

https://doi.org/10.1016/j.addma.2019.100920

Link to publication record in Ulster University Research Portal

Published in:

Additive Manufacturing

Publication Status:

Published (in print/issue): 01/01/2020

DOI:

10.1016/j.addma.2019.100920

\section{Document Version}

Version created as part of publication process; publisher's layout; not normally made publicly available

\section{General rights}

Copyright for the publications made accessible via Ulster University's Research Portal is retained by the author(s) and / or other copyright owners and it is a condition of accessing these publications that users recognise and abide by the legal requirements associated with these rights.

\section{Take down policy}

The Research Portal is Ulster University's institutional repository that provides access to Ulster's research outputs. Every effort has been made to ensure that content in the Research Portal does not infringe any person's rights, or applicable UK laws. If you discover content in the Research Portal that you believe breaches copyright or violates any law, please contact pure-support@ulster.ac.uk. 


\section{Journal Pre-proof}

Production and characterization of PEEK/IF-WS 2 nanocomposites for Additive Manufacturing: simultaneous improvement in processing characteristics and material properties

Atefeh Golbang, Eileen Harkin-Jones, Marcin Wegrzyn, Gavin Campbell, Edward Archer, Alistair Mcllhagger

PII: S2214-8604(19)30693-1

DOI: $\quad$ https://doi.org/10.1016/j.addma.2019.100920

Reference: $\quad$ ADDMA 100920

To appear in: $\quad$ Additive Manufacturing

Received Date: $\quad 3$ June 2019

Revised Date: $\quad 27$ September 2019

Accepted Date: $\quad 16$ October 2019

Please cite this article as: Golbang A, Harkin-Jones E, Wegrzyn M, Campbell G, Archer E, Mcllhagger A, Production and characterization of PEEK/IF-WS ${ }_{2}$ nanocomposites for Additive Manufacturing: simultaneous improvement in processing characteristics and material properties, Additive Manufacturing (2019), doi: https://doi.org/10.1016/j.addma.2019.100920

This is a PDF file of an article that has undergone enhancements after acceptance, such as the addition of a cover page and metadata, and formatting for readability, but it is not yet the definitive version of record. This version will undergo additional copyediting, typesetting and review before it is published in its final form, but we are providing this version to give early visibility of the article. Please note that, during the production process, errors may be discovered which could affect the content, and all legal disclaimers that apply to the journal pertain.

(C) 2019 Published by Elsevier. 


\title{
Production and characterization of PEEK/IF-WS ${ }_{2}$ nanocomposites for Additive Manufacturing: simultaneous improvement in processing characteristics and material properties
}

\author{
Atefeh Golbang ${ }^{1}$, Eileen Harkin-Jones ${ }^{1 *}$, Marcin Wegrzyn ${ }^{1}$, Gavin Campbell ${ }^{2}$, Edward \\ Archer $^{1}$, Alistair McIlhagger ${ }^{1}$ \\ ${ }^{1}$ Ulster University - Jordanstown, BT37 0QB, Email: e.harkin-jones@ulster.ac.uk \\ ${ }^{2}$ Bombardier Aerospace. 2 Airport Rd, Belfast BT3 9EU, UK
}

\begin{abstract}
Successful printing of high-performance material with suitable properties using additive manufacturing methods such as Fused Filament Fabrication (FFF) can create many advanced applications in industries. However, the high viscosity of high-performance polymers causes complications during the FFF process and reduces the final print quality. To overcome this challenge, Inorganic Fullerene Tungsten Sulphide (IF-WS 2 ) nanoparticles are applied in this study to enhance the flowability of poly-ether-ketone-ketone (PEEK) without compromising its mechanical and thermal properties. In the first step, different loadings of IF-WS 2 nanoparticles are melt compounded with PEEK and the nanocomposites are characterized. SEM and EDX images of fractured surfaces indicate that a good dispersion of nanoparticles is achieved without any pre-treatment or pre-dispersion. A reduction in melt viscosity of $25 \%$, and a simultaneous growth in storage modulus, crystallization and degradation temperature of about $60 \%, 53 \%$ and $100{ }^{\circ} \mathrm{C}$ is found with addition of $2 \mathrm{wt} \%$ IF-WS 2 to PEEK, respectively.
\end{abstract}


This great achievement is mainly ascribed to the unique characteristics of IF-WS 2 nanoparticles, acting as both reinforcing and lubricating agents, indicated by a reduction in coefficient of friction. There is no significant increase of crystallization and melting temperatures with the addition of IF-WS 2 nanoparticles, which is beneficial in the FFF process. In the second step, the PEEK nanocomposite filaments are printed via FFF. The print quality and mechanical properties of the printed PEEK are also improved with the incorporation of IF$\mathrm{WS}_{2}$ nanoparticles. Hence, incorporation of IF-WS 2 nanoparticles into PEEK via melt compounding is an effective approach for the development of suitable high-performance engineering materials for FFF.

Keywords: Poly Ether Ether Ketone (PEEK); Inorganic Fullerene Tungsten Sulphide (IF$\mathrm{WS}_{2}$ ); viscosity; Fused filament fabrication (FFF); Additive Manufacturing (AM)

\section{1- Introduction}

Fused filament fabrication (FFF) is a cost-effective additive manufacturing (AM) methods for producing complex thermoplastic parts. During the FFF process, a thermoplastic filament passes through a heated nozzle and a semi-liquid thermoplastic material is deposited onto a printing bed or a previous thermoplastic layer ${ }^{1-3}$. The zero-shear rate viscosity has a critical effect on filament extrusion during FFF because the semi-liquid thermoplastic polymer is forced through the nozzle at relatively low shear rates. If the polymer viscosity is too high then the back pressure on the filament is also high and this can cause buckling of the filament and no/reduced flow through the nozzle ${ }^{4,5}$. 
Poor layer to layer adhesion is one of the main challenges of FFF which results in reduced mechanical properties. Polymer viscosity can have a great effect on bond formation and strength between the layers. Deposition of a low viscous material on top of a previously deposited layer can facilitate wetting between the layers and create a larger interface. Generally, the adhesion between the printed layers increases with decrease in melt viscosity, mainly due to higher polymer chain mobility and intermingling between the adjacent layers. Some studies suggest that in the case of semi-crystalline polymers, layer-layer bonding forms through both interdiffusion of chains (above the crystalline temperature) and co-crystallization. Hence, the rheology of the feed material is a determining factor in final quality and mechanical properties of parts produced via FFF ${ }^{6-9}$.

Some of the most commonly used materials in FFF consist of amorphous thermoplastics (e.g. ABS) and semi-crystalline polymers with low melting point (e.g. PLA) because they generally have good flowability. However, the final 3D printed part made from low viscosity polymers often fail in applications where high mechanical or thermal properties are required. Successful printing of high-performance material with suitable properties using additive manufacturing processes such as FFF can offer many advanced industrial applications. The high strength-to-weight ratio and superior properties of high-performance polymers compared to traditional thermoplastics, makes them a good candidate for replacing metals. Hence, customization of high-performance material to additive manufacturing is the key to providing a broad range of applications in industries such as aerospace, biomedical, robotics, electronics, transportation and telecommunications, etc. Currently, there is limited number of highperformance material commercially available for use in the FFF process and there is an evergrowing demand in this area ${ }^{7,8,10}$.

One high-performance material of significant interest is poly ether ether ketone (PEEK) which is a semi-crystalline polymer with excellent mechanical properties, thermal stability, 
chemical resistance and biocompatibility ${ }^{10}$. However, the high viscosity of PEEK causes challenges during FFF processing and adversely affects the final print quality. Generally, high temperatures are required to melt and reduce the viscosity of PEEK for printing. On the other hand, as PEEK cools down after deposition, its viscosity increases rapidly; this interrupts polymer interdiffusion and hence bond formation between the layers. Flow induced crystallization is also pronounced due to the high viscosity of PEEK which can increase the crystallization temperature, allowing the polymer to solidify at higher temperatures. This can have a negative impact on bond formation and adhesion strength between the layers ${ }^{6,11-13}$.

Traditionally, plasticisers or grades of PEEK with lower molecular weight are applied to reduce melt viscosity. However, the mentioned methods can also reduce the mechanical properties and therefore limit the applicability of the final product ${ }^{14,15}$. Hence, in order to make PEEK into a suitable feed material for FFF, it is essential to improve PEEK flowability without compromising its final mechanical properties.

Inorganic fullerene-like tungsten disulfide (IF-WS $)$ nanoparticles have recently attracted a lot of attention due to their exceptional mechanical, thermal, electrical and tribological properties originating from their chemical structure and unique multi-layered 'onion-like' morphology. IF-WS2 nanoparticles are considered as superior solid lubricants which enhance the toughness and reduce the coefficient of friction (COF) of polymers ${ }^{16,17}$. Hou et. al. demonstrated that the coefficient of friction (COF) of PEEK/IF-WS 2 nanocomposite coatings decreases by $70 \%$ compared to that of pure PEEK with the addition of $2.5 \mathrm{wt} . \%$ IF-WS 2 through solution mixing followed by aerosol-assisted deposition and post treatment at high temperatures ${ }^{18}$. Naffakh et. al. showed that the incorporation of $0.1 \mathrm{wt} . \%$ IF-WS 2 in PEEK through solution mixing and ultra-sonication enhances the impact strength of PEEK by $20 \%$. They also observed a 35\% improvement in Young's modulus with the addition of $2 \mathrm{wt} \%$ IF$\mathrm{WS}_{2}$, as a result of the reinforcing effect of these nanoparticles, and improvement in 
crystallization in the presence of IF-WS ${ }_{2}{ }^{19}$. The same authors also reported an improvement in the thermal stability of iPP/IF-WS 2 nanocomposites, of about $40{ }^{\circ} \mathrm{C}$, and $60{ }^{\circ} \mathrm{C}$ in air and inert atmosphere, respectively. Combination of IF-WS2 nanoparticles with SWCNTs has been successful for improving SWCNT dispersion in thermoplastics, leading to higher glass transition temperature in addition to easier processability and lower cost ${ }^{20}$. However, a progressive drop in both viscosity and storage modulus was realized with increasing IF-WS loading in SWCNT/PEEK nanocomposites ${ }^{21}$.

Another characteristic of IF-WS 2 nanoparticles which may be exploited in FFF is their high thermal conductivity ${ }^{22}$. It has been shown previously that enhanced heat transfer during melting and layer deposition in FFF, can improve layer to layer bonding between the deposited filaments ${ }^{23}$.

Based on the above discussion, the combined advantages of PEEK (as a high- performance polymer) and IF-WS 2 nanoparticles (as nano-additives with excellent reinforcing and lubricating effects), can offer new potential in the development of suitable feed material for FFF. In this work, melt compounded IF-WS 2 /PEEK nanocomposite filaments are produced and characterized through mechanical, thermal, tribological and rheological testing. No ball milling or pre-dispersion step is applied, and the nanoparticles are directly mixed with PEEK granules using a screw configuration designed in-house for excellent dispersion of nanoparticles. The viscoelastic behaviour and flowability of the material are evaluated and compared with unfilled PEEK, since these parameters affect the printability, layer to layer adhesion and ultimately the quality of the printed part. Finally, FFF is used to print the filaments into bars for evaluating the mechanical performance of the printed parts. The details of print quality of FFF printed PEEK/IF-WS 2 nanocomposites in comparison to that of pure PEEK are examined as an extension to this study and the results are to be published in a future. 


\section{Materials and Methods}

\subsection{Sample preparation}

Inorganic fullerene like Tungsten di-sulfide (IF-WS $)$ nanoparticles with a spherical shape and average diameter of about $80 \mathrm{~nm}$ were supplied by Professor Yanqui Zhu's group at the University of Exeter. The matrix used was a commercially available semi-crystalline poly (ether ether ketone), PEEK 450G, supplied by Victrex, $\left(\mathrm{Mw} \approx 44000 \mathrm{~g} / \mathrm{mol}, \mathrm{Tg} \approx 143{ }^{\circ} \mathrm{C}\right.$, $\left.\mathrm{Tm} \approx 343{ }^{\circ} \mathrm{C}\right)$. Various amounts of IF-WS 2 nanoparticles $(0.5,1$ and $2 \mathrm{wt} \%)$ were melt compounded with PEEK using a twin-screw extruder with $16 \mathrm{~mm}$ diameter, length to diameter ratio (L/D) of 40, and screw speed of $30 \mathrm{rpm}$ to produce filaments with an average diameter of $1.75 \pm 0.15 \mathrm{~mm}$. An extruder screw configuration designed in-house to enhance nanoparticle dispersion was utilized (Figure 1). The material flow is from left to right in the picture presented in Figure 1. The screw elements are composed of transporting elements $(\mathrm{T})$ for forward conveying of extrudate, kneading elements $(\mathrm{K})$ with $90^{\circ}, 60^{\circ}$ and $30^{\circ}$ twist angles for dispersion, and reverse screw element $(\mathrm{R})$. The temperatures indicated in each zone of the extruder are as follows: $365,395,395,395,395,395,395,395,390,385^{\circ} \mathrm{C}$.

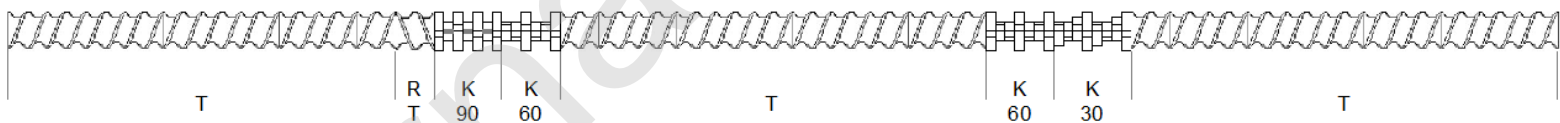

Figure 1 Screw design used for processing of PEEK/IF-WS 2 filaments

The flowability and thermal properties of the nanocomposite filaments were characterized using rheology, DSC and TGA. The filaments were then pelletized and processed into rectangular specimens through injection moulding (using a Haake MiniJet Pro injection moulding machine) for morphology characterization as well as mechanical and tribological testing. The temperature of the cylinder and mould were set at $400{ }^{\circ} \mathrm{C}$ and $260{ }^{\circ} \mathrm{C}$ for injection moulding. In addition, specimens with similar dimensions to the injection moulded samples 
were printed from the extruded filaments using FFF (Ultimaker) to comparing mechanical properties via DMA. The printing speed, building plate temperature, nozzle temperature and nozzle diameter were set at $40 \mathrm{~mm} / \mathrm{s}, 260{ }^{\circ} \mathrm{C}, 400{ }^{\circ} \mathrm{C}$ and $2 \mathrm{~mm}$, respectively. The build chamber was not heated for printing and the ambient environment temperature was $20^{\circ} \mathrm{C}$. The bed temperature was kept at constant temperature of $260{ }^{\circ} \mathrm{C}$. To produce relatively uniform samples, $\pm 45^{\circ}$ raster orientation was applied. A comparison was made between the mechanical properties of the printed and the injection moulded samples.

\subsection{Characterization}

The fractured surfaces of the injection moulded specimens were gold coated and observed using a high resolution FEG SEM (HITACHI) equipped with EDX, operating at $30 \mathrm{kV}$ and an intensity of $9 \times 10^{-9} \mathrm{~A}$ in order to assess IF-WS 2 nanoparticles dispersion in PEEK.

The impact strength of the injection moulded specimens was measured according to ISO 180:2000. Specimen dimensions were length $=33 \mathrm{~mm}$, width $=10 \mathrm{~mm}$ and thickness $=3 \mathrm{~mm}$, with a $\mathrm{V}$-shape notch of tip radius $=0.25 \mathrm{~mm}$ and depth $=2 \mathrm{~mm}$.

For evaluating the thermal stability of the nanocomposite filaments, a TA SDT Q600D thermogravimetric analysis (TGA) machine was used at a heating rate of $10{ }^{\circ} \mathrm{Cmin}^{-1}$ under nitrogen. The average sample mass was $10 \mathrm{mg}$.

The crystallization and melting behaviour of the nanocomposite filaments were investigated using a TA-Instrument Q1000 differential scanning calorimetry. The samples of approximately $5 \mathrm{mg}$ weight, were sealed in aluminium pans and a heating-cooling-heating cycle between 20 to $400{ }^{\circ} \mathrm{C}$ at $10{ }^{\circ} \mathrm{C} / \mathrm{min}$ in standard mode was applied. Crystallinity $\left(\chi_{\mathrm{c}}\right)$ was calculated from the crystallization peak, as shown by Tradif et $\mathrm{al}^{24}$. 
Dynamic shear tests were carried out for PEEK nanocomposite pellets at $400{ }^{\circ} \mathrm{C}$ with a shear amplitude of $1 \%$ (which is in the linear viscoelastic region) using a AR 1000 rheometer with a parallel plate system ( $25 \mathrm{~mm}$ diameter and $0.75 \mathrm{~mm}$ gap).

The dynamic mechanical performance of the injection moulded and 3D printed nanocomposite samples was studied using a Mettler TA800 DMA. Rectangular shaped samples of $19.5 \cdot 10 \cdot 4 \mathrm{~mm}^{3}$ were placed in a single cantilever clamp. The measurements were performed in the bending mode via single cantilever at a frequency of $1 \mathrm{~Hz}$, with a heating rate of $2{ }^{\circ} \mathrm{C} / \mathrm{min}$ from $25^{\circ} \mathrm{C}$ to $260{ }^{\circ} \mathrm{C}$.

The static and dynamic frictional properties of injection moulded nanocomposite samples were investigated based on ASTM D1894. ASTM52100 was used to perform micro-scale abrasion tests with the use of a TE-66 micro-scale abrasion equipment (Phoenix Tribology Ltd, UK) as demonstrated by Sampaio et. $\mathrm{al}^{25}$.

The print quality of the 3D printed samples was visually examined using an Olympus Microscope with a magnification of 10 .

\section{Results and Discussion}

\subsection{Specific Mechanical Energy (SME)}

The Specific Mechanical Energy (SME) for compounding of PEEK and IFWS $2 /$ PEEK nanocomposite samples is calculated based on equation 1 and presented in figure 2 as a function of IF-WS2 wt\%. SME in $\mathrm{kW} / \mathrm{kg}$ per hr, represents the mechanical energy for extrusion of a unit mass of compound per hour (m).

$$
\mathrm{SME}=\left(\mathrm{P} \times \% \mathrm{~T} \times \mathrm{RPM}_{\mathrm{running}} / \mathrm{RPM}_{\max }\right) / \mathrm{m} \quad \text { eq }(1)
$$


Where $\mathrm{P}$ is the applied motor power in $\mathrm{kW}, \% \mathrm{~T}$ is the percentage of running torque used of the maximum allowable torque, RPMrunning is the actual screw speed of the extruder and $\mathrm{RPM}_{\max }$ is the maximum screw speed of the extruder.

As illustrated, the SME for PEEK decreases with the incorporation of IF-WS2 nanoparticles, perhaps due to the lubricating effect of these nanoparticles which reduces the viscosity of the melt. This also indicates favourable characteristics for the FFF process since extrusion back pressures and filament buckling should reduce ${ }^{26}$.

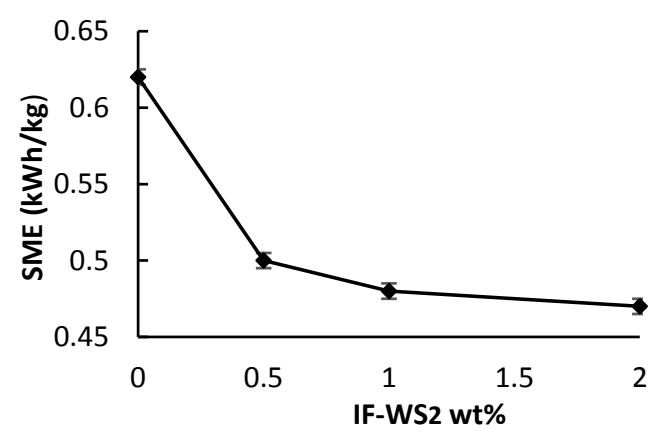

Figure 2 Specific Mechanical Energy (SME) for compounding of PEEK and IFWS $2 /$ PEEK nanocomposites

\subsection{Scanning Electron Microscopy (SEM)}

The morphology of PEEK/IF-WS 2 nanocomposites with different nanoparticle loading is shown in the SEM images in Figure 3a, b and c. The EDX mapping and spectrum for the PEEK nanocomposite sample containing $0.5 \mathrm{wt} \% \mathrm{IF}_{-\mathrm{WS}}$ is also presented in figure $3 \mathrm{~d}$ and e to demonstrate the elemental composition of the nanocomposite.

The IF-WS 2 nanoparticles appear as white spots in the SEM images, with quasi-spherical shape and dimensions ranging from about $50 \mathrm{~nm}$ to about $200 \mathrm{~nm}$ which is in the range of the as-received material. This means that the nanoparticles have been dispersed homogeneously inside the PEEK matrix through melt blending, without any pre-dispersion or pre-treatment step. The low tendency for agglomeration in these samples can be attributed to the unique 
microstructure of IF-WS $\mathbf{2}$ nanoparticles which leads to exceptional lubricating behaviour during processing, resulting in a more uniform nanoparticle dispersion.

Also apparent from the SEM images is that the mechanism of fracture toughness in the nanocomposite samples is mainly nanoparticle debonding, some particle pull-out (especially in the case of samples with 0.5 and $2 \mathrm{wt} \%$ IF-WS 2 ), as well as plastic void growth, followed by shear deformation in the polymer matrix ${ }^{27}$.

The various colours in the EDX mapping and the peaks in the EDX spectrum, represents carbon $(\mathrm{C})$, oxygen $(\mathrm{O})$, tungsten $(\mathrm{W})$, sulphur $(\mathrm{S})$ elements. The peaks representing gold $(\mathrm{Au})$ and palladium $(\mathrm{Pd})$ elements exist as a result of coating performed on the samples.
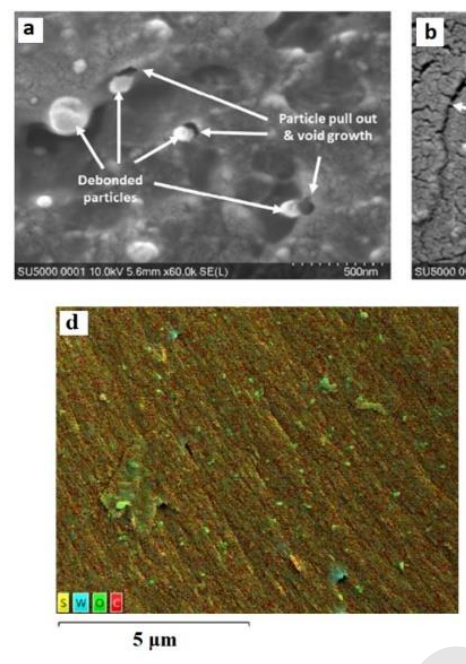
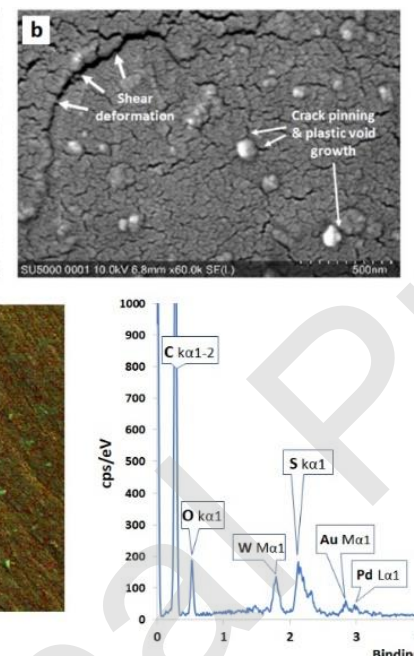

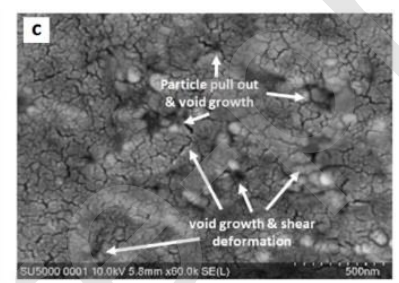

e

Figure 3 SEM images of PEEK nanocomposites containing a) $0.5 \mathrm{wt} \%$, b) $1 \mathrm{wt} \%$ c) $2 \mathrm{wt} \%$ IFWS2, d) EDX mapping and e) EDX analysis of sample containing 0.5wt $\%$ IF-WS 2

\subsection{Fracture Toughness}

It is observed from the data presented in figure 4 that the impact strength of PEEK is generally increased with the addition of IF-WS 2 nanoparticles, which is good for potential applications for IF-WS 2 /PEEK nanocomposites where any reduction in toughness would not be acceptable. 
The sample containing $1 \mathrm{wt} \%$ IF-WS $\mathbf{2}$ has the maximum improvement in impact strength. Therefore, it can be presumed that there is better nanoparticle dispersion and therefore higher filler-polymer interaction in this sample as a result of the larger surface area between the filler and the matrix for load transfer and consequently, higher impact strength. The decreased impact strength in the sample with $2 \mathrm{wt} \%$ IF-WS 2 may be due to an increased tendency for agglomeration in this sample. This trend is confirmed in the SEM images (figure 1); there is more particle de-bonding in the $1 \mathrm{wt} \%$ nanocomposite sample as compared to the other two nanocomposite samples, whereas, some particle pull-out (indicated by holes with similar size to that of the particles on the fracture surface) is visible in the 0.5 and $2 \mathrm{wt} \%$ PEEK/IF-WS 2 nanocomposites, which is indicative of weaker filler-polymer interaction. Interfacial debonding relieves the constraint in the polymer matrix and allows plastic deformation, thus increasing the toughness. This explains the maximum toughness value at $1 \mathrm{wt} \% \mathrm{IF}-\mathrm{WS}_{\mathbf{2}}{ }^{19,27,28}$.

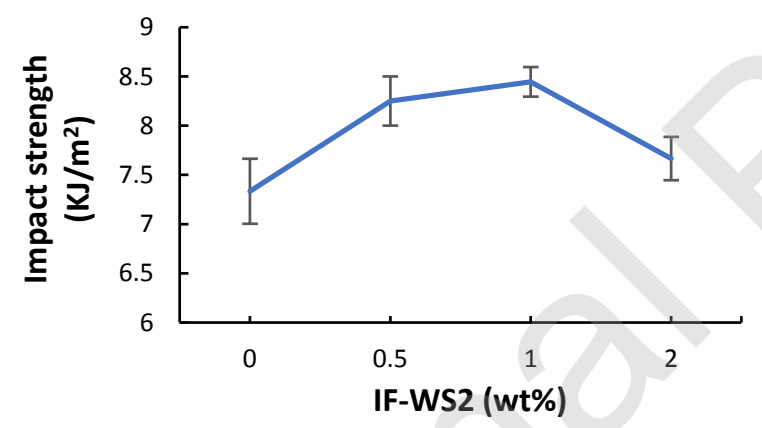

Figure 4 Impact strength of PEEK samples containing various amounts of IF-WS 2

\subsection{Thermal Properties}

Changes in thermal degradation of IF-WS 2 /PEEK nanocomposite samples with temperature are illustrated in figure 5. The thermal stability of the nanocomposites increases with increase in nanofiller content as a result of high thermal resistivity of IF-WS 2 nanoparticles. However, at $2 \mathrm{wt} \% \mathrm{IF}-\mathrm{WS}_{2}$ loading, the enhancement in thermal stability is smaller; most probably due to some degree of nanoparticle agglomeration in this sample. 


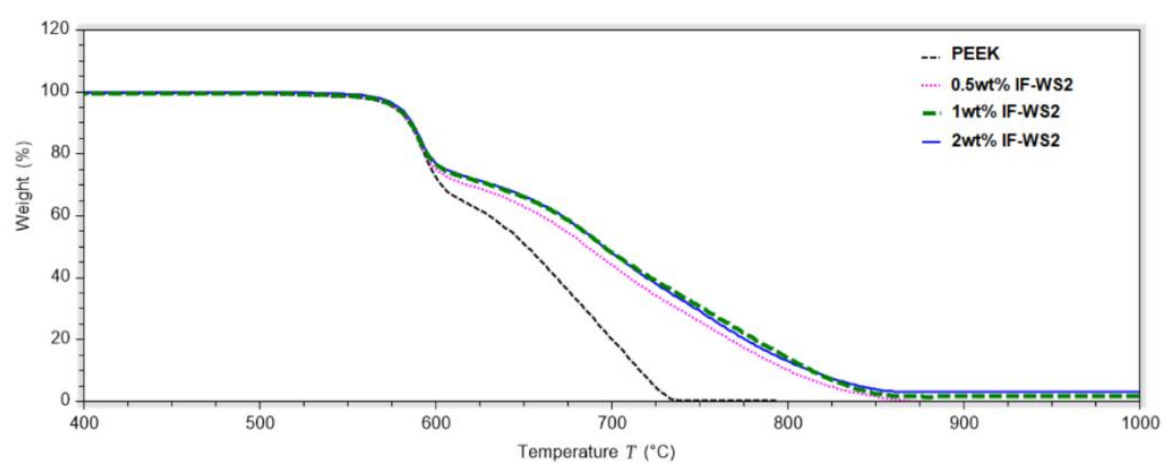

Figure 5 Variation of sample weight with temperature for PEEK samples with 0, 0.5, 1 and $2 \mathrm{wt} \% \mathrm{IF}-\mathrm{WS}_{2}$

The crystallinity of the PEEK samples increases with addition of IF-WS $\mathbf{2}$ nanoparticles, as illustrated in figure 6a. The crystallization degree initially increases up to $1 \mathrm{wt} \%$ IF-WS2

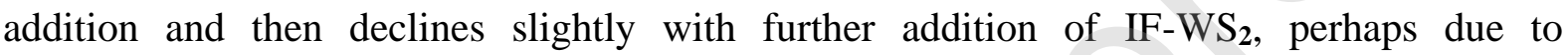
agglomeration of NPs in the $2 \mathrm{wt} \%$ IF-WS 2 sample. Any increase in the crystallization temperature of a polymer due to the nucleation effect of added particles can be a disadvantage in FFF because it results in less time for polymer chain diffusion and bond formation between the layers ${ }^{19,24}$. However, in this work there is only a $1{ }^{\circ} \mathrm{C}$ increase in in the crystallization temperature with the addition of IF-WS 2 nanoparticles (figure 6b), which is not a significant change. It is worth noting that, there was also no obvious change in the PEEK melting point with the incorporation of IF-WS 2 nanoparticles.
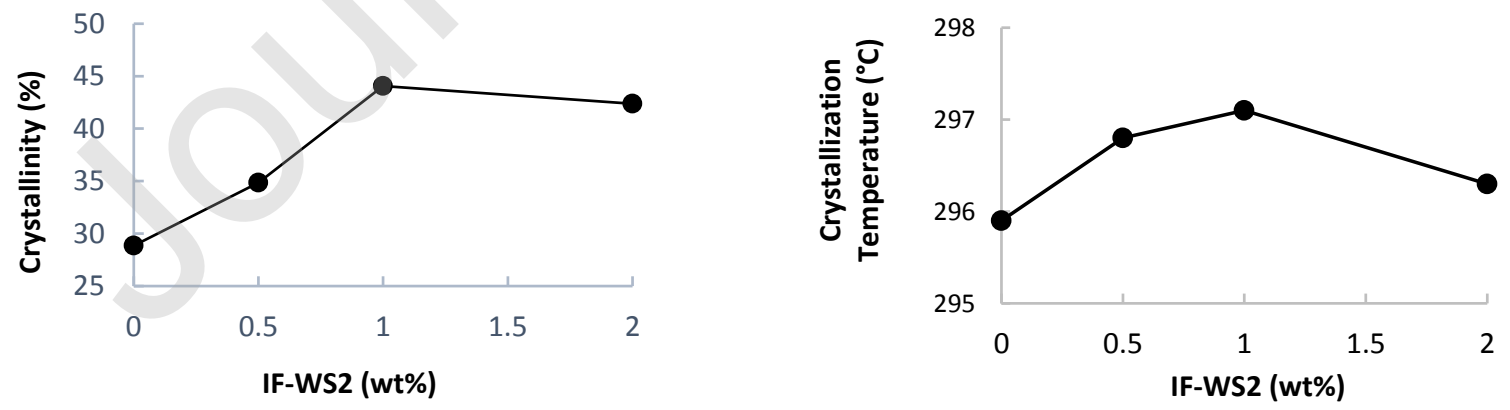

Figure 6 a) changes in crystallinity (\%) and b) crystallization temperature vs IF-WS 2 content 
The enhancement in crystallinity of PEEK in the presence of IF-WS 2 nanoparticles can be mainly ascribed to the lubricating effect of IF-WS 2 nanoparticles which facilitate polymer chain movement and therefore crystal growth through diffusion and arrangement of polymer chains with higher lengths 29,30 .

\subsection{Tribology}

The coefficient of friction (static and dynamic), as well as wear rate of the nanocomposite samples were measured to confirm the lubricant effect of the IF-WS 2 . As depicted in figure 7 $\mathrm{a}$ and $\mathrm{b}$, addition of IF-WS $\mathrm{W}_{\mathbf{2}}$ nanoparticles reduces both coefficients of friction and wear rate of PEEK. Unfilled PEEK exhibits a static CoF of around 0.23 that reduces by $10 \%$ with the addition of $1.0 \mathrm{wt} \%$ IF-WS2. Additionally, the wear rate of PEEK decreases by about $50 \%$ by incorporating $2.0 \mathrm{wt} \% \mathrm{IF}_{-\mathrm{WS}_{2} \text {. It is believed that, the spherically shaped IF-WS }}$ nanoparticles can roll between the surfaces similarly to ball-bearing agents, effectively decreasing the coefficient of friction as evidenced by tribological test results. On the hand, it is discussed that the outstanding tribological properties observed in IF-WS 2 thermoplastic nanocomposites is due to various mechanisms such as sliding, rolling and outer layers exfoliating/peeling of the IF-WS $_{2}$ nanoparticles, which result in the formation of a tribo-film ${ }^{16,31}$.
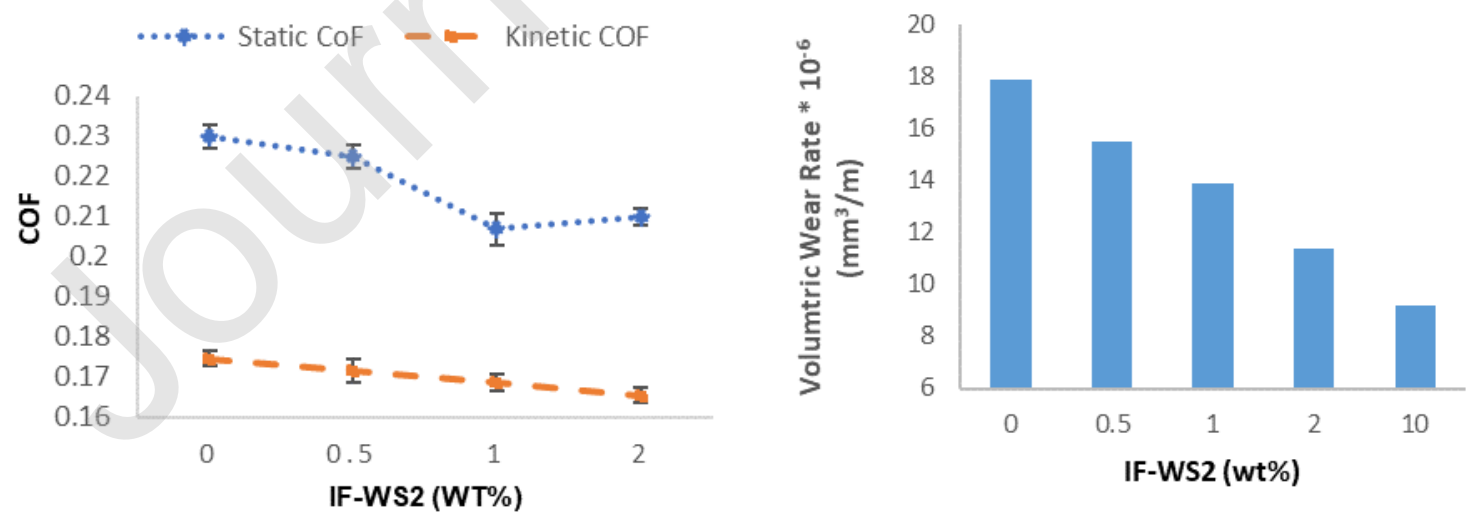

Figure 7 a) Static and dynamic coefficient of friction and b) wear rate for PEEK samples containing different loadings of IF-WS 2 


\subsection{Rheology}

Changes in shear viscosity with shear rate for PEEK and PEEK/IF-WS 2 nanocomposite samples are illustrated in figure 8. There is initially an increase in viscosity with the addition of $0.5 \mathrm{wt} \%$ IF-WS 2 in comparison with the unfilled PEEK, but then a progressive reduction of viscosity is observed with further addition of IF-WS 2 . For example, at a shear rate of $0.1 \mathrm{~s}^{-1}$, there is around a $25 \%$ reduction in shear viscosity of PEEK with the addition of $2 \mathrm{wt} \%$ IF-WS2. The difference in viscosity of samples becomes less pronounced in the higher-shear rate range.

The observed reduction in viscosity at low shear rates with increase in IF-WS $\mathrm{W}_{2}$ content differs from the typical behaviour expected for polymer/nanoparticle nanocomposites, in which $\eta$ generally grows with increase in nanofiller concentration. This different behaviour may be related to the lubricating effect of the IF-WS 2 nanoparticles (as demonstrated by tribological tests), resulting in polymer chain slippage across the smooth surface of quasi-spherical IF-WS nanoparticles, hence improving the flow of the polymer chains under the applied shear rate ${ }^{21}$. Another reason for the drop in $\eta$ is the possibility of higher heat transfer in the samples containing 1 and $2 \mathrm{wt} \%$ IF-WS2 due to higher thermal conductivity of these nanoparticles in comparison to pure $\mathrm{PEEK}^{22}$.

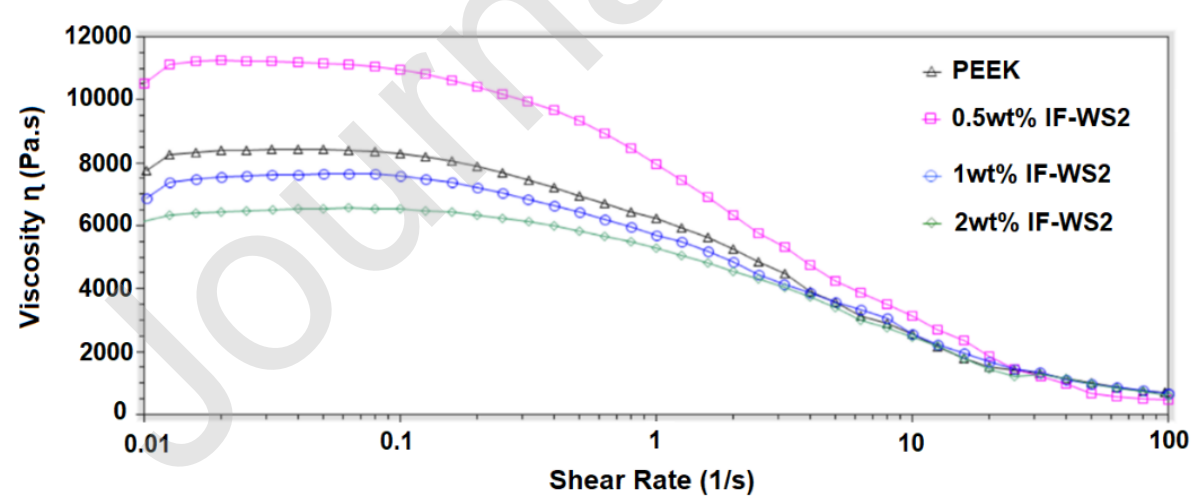

Figure 8 shear viscosity versus shear rate for PEEK samples containing different amounts of $\mathrm{IF}_{-\mathrm{WS}}$ 
The shear thinning behaviour observed for all the nanocomposites will improve polymer flow through the liquefier and the nozzle during FFF at shear rates lower than $10 \mathrm{~s}^{-1}$ which may occur at the low deposition rates and high nozzle diameters required for PEEK extrusion. More importantly, the reduction in zero shear viscosity (i.e. shear viscosity at very low shear rates) can contribute to layer to layer adhesion improvement through enhanced chain mobility and diffusion across the interface ${ }^{7}$. Hence, the nanocomposites containing 1 and $2 \mathrm{wt} \%$ IF-WS should perform better in FFF than pure PEEK in terms of mechanical properties in the zdirection.

\subsection{Dynamic Mechanical Analysis (DMA)}

The changes in the storage modulus $\left(\mathrm{E}^{\prime}\right)$ and loss tangent $(\tan \delta)$ for injection moulded and printed samples with different IF-WS 2 loading as a function of temperature, at fixed frequency $(1 \mathrm{~Hz})$ are presented in figures 9 and 10 . In addition, the values of storage modulus at $120{ }^{\circ} \mathrm{C}$ and glass transition temperature $(\mathrm{Tg})$ based on $\tan \delta$ peak for the injection moulded and printed samples are compared and presented in Table 1.

The storage modulus generally increases with the addition of IF-WS 2 nanoparticles, especially below the glass transition temperature region. However, the enhancement of storage modulus for the samples prepared via injection moulding is higher in comparison with 3D printing (Table 1). The observed difference can be due to higher packing density and perhaps improved nanoparticle dispersion due to the applied pressure during injection moulding. Enhanced crystallinity as a result of lower cooling rate during injection moulding may be another reason for the observed difference. During printing, the layers are exposed to a room temperature environment and since the layer thickness is relatively small, the cooling rate is generally faster than in the case of injection moulded samples with mould temperature of 260 ${ }^{\circ} \mathrm{C}$. When cooling rate is higher, there is not enough time for the polymer chains to align and 
pack to form perfect crystals. Hence, the lower increment in $\mathrm{E}^{\prime}$ for the printed nanocomposites can be attributed to higher free volume and imperfect crystals in these samples ${ }^{32}$.

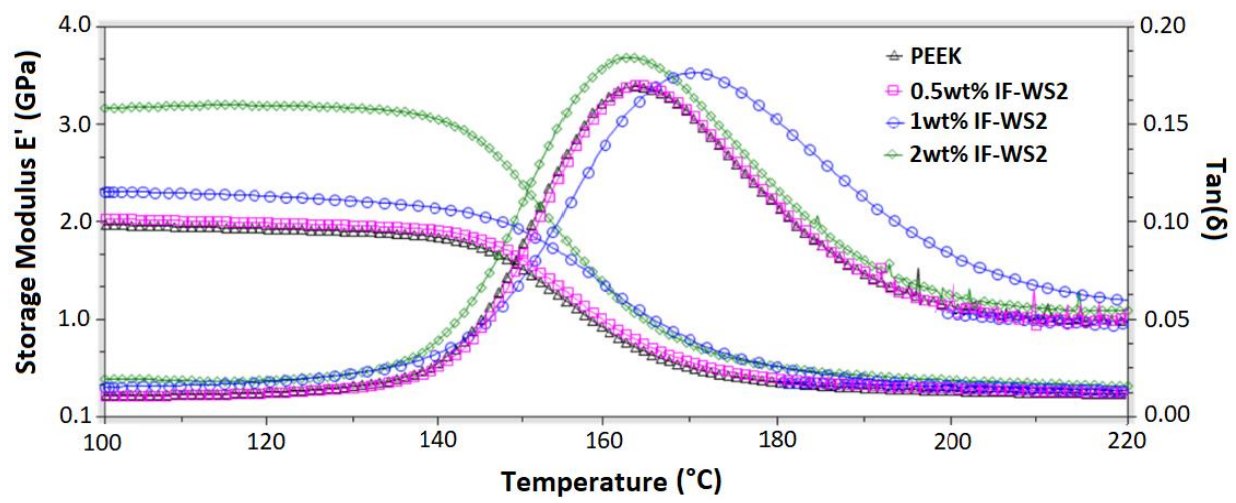

Figure 9 Storage modulus $\left(\mathrm{E}^{\prime}\right)$ and Loss tangent $(\tan \delta)$ vs temperature for injection moulded PEEK samples

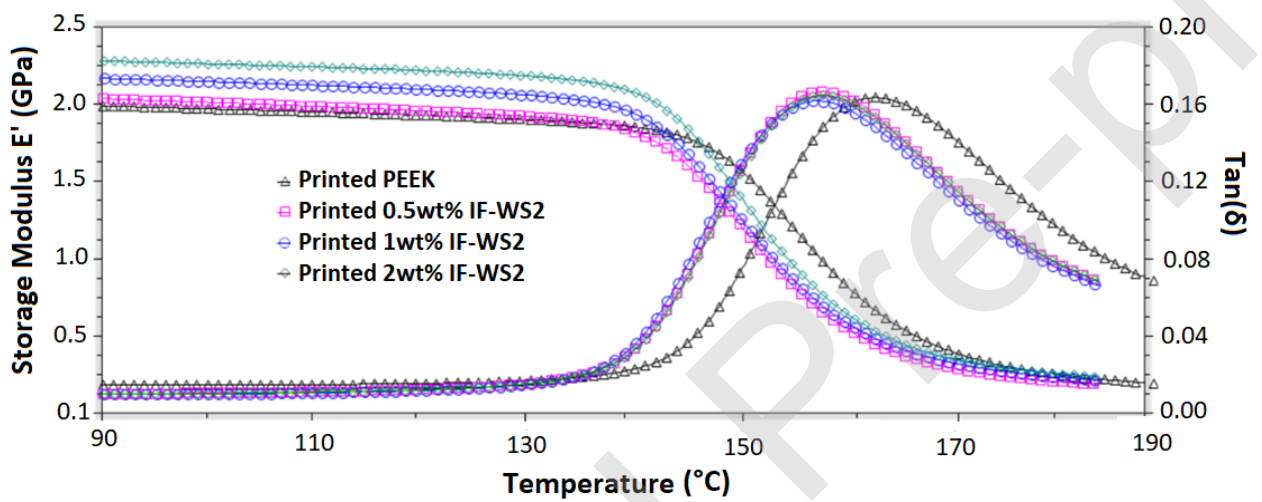

Figure 10 Storage modulus $\left(\mathrm{E}^{\prime}\right)$ and Loss tangent $(\tan \delta)$ vs temperature for printed PEEK samples

A key objective of this work was to improve the printability and performance of PEEK in FFF by incorporating IF-WS2 nanoparticles into the PEEK. It is interesting to see that with only $1.0 \mathrm{wt} \%$ loading of IF-WS2 nanoparticles in PEEK the FFF sample modulus has exceeded the modulus of the unfilled injection moulded PEEK by $9 \%$.

From the $\tan \delta$ curves and the information provided in Table 1, it is noted that the glass transition temperature is dependent not only on the amounts of IF-WS 2 nanoparticles, but also the method of sample preparation. For the injection moulded samples, there is a shift of around 
$9{ }^{\circ} \mathrm{C}$ in $\mathrm{T}_{\mathrm{g}}$ towards higher temperatures for the nanocomposite sample with $1 \mathrm{wt} \%$ IF-WS compared to pure PEEK, while there is no noticeable change in the position of $\mathrm{T}_{\mathrm{g}}$ for the other two nanocomposite samples. This may be due to the improved nanoparticle dispersion in the $1 w t \%$ IF-WS 2 sample, which can result in enhanced NP-polymer interactions. Also, the extension of the tan $\delta$ peak to higher temperatures for the $1 \mathrm{wt} \%$ IF-WS 2 indicates the expansion of relaxation time during the glass transition, which supports the idea of an interphase with polymer chain mobility different from that of the bulk polymer. The increment in $\mathrm{Tg}$ in this sample is remarkable, considering that no mechanical or chemical pre-dispersion step was applied in this work and the nanoparticles were directly mixed with PEEK granules ${ }^{19}$.

The larger area of the tan $\delta$ curve for the samples containing 1 and $2 \mathrm{wt} \%$ IF-WS $\mathbf{W}_{\mathbf{2}}$ can also be linked to the lubricating behaviour of IF-WS 2 nanoparticles, promoting chain mobility during relaxation (i.e. glass transition), resulting in higher energy damping.

Table 1 Comparison between $\mathrm{E}^{\prime}$ and Tg of injection moulded and 3D printed PEEK samples

\begin{tabular}{|l|l|l|l|l|l|l|}
\hline & \multicolumn{2}{|l|}{ Injection Moulded Samples } & \multicolumn{2}{l|}{ 3D Printed Samples } \\
\hline IF-WS2 (wt\%) & $\mathrm{E}^{\prime}(\mathrm{GPa})$ & ${ }^{*} \mathrm{E}^{\prime} / \mathrm{E}^{\prime}(\%)$ & $\mathrm{Tg}\left({ }^{\circ} \mathrm{C}\right)$ & $\mathrm{E}^{\prime}(\mathrm{GPa})$ & ${ }^{*} \mathrm{E}^{\prime} / \mathrm{E}^{\prime}(\%)$ & $\mathrm{Tg}\left({ }^{\circ} \mathrm{C}\right)$ \\
\hline 0 & 1.97 & - & 161 & 1.88 & - & 160 \\
\hline 0.5 & 2.06 & 4.6 & 161 & 1.94 & 3.19 & 157 \\
\hline 1 & 2.36 & 19.3 & 170 & 2.15 & 14.36 & 157 \\
\hline 2 & 3.14 & 59.4 & 162 & 2.29 & 21.8 & 157 \\
\hline
\end{tabular}

*\% increase in $\mathrm{E}^{\prime}$ of IF-WS $2 / \mathrm{PEEK}$ nanocomposite samples in respect to that of unfilled PEEK

For the $3 \mathrm{D}$ printed samples, there is a slight reduction of glass transition temperature in the nanocomposite samples compared to pure PEEK. Since there is no applied pressure during printing and the cooling rate is higher, the packing density of polymer chains is expected to be lower. Hence, the lubricating action of IF-WS 2 nanoparticles can be accommodated by higher 
free volume in the printed samples which results in enhanced polymer chain mobility and consequent reduction of the glass transition temperature ${ }^{33}$.

The next stage of this study will be focus on optimization of FFF printing parameters to further enhance the mechanical properties of printed IF-WS $2 /$ PEEK nanocomposites.

\subsection{FFF printing}

The print quality of samples was checked under a microscope as illustrated in figure 11 . There are some non-uniformities and voids visible (circled) in the unfilled PEEK samples. However, there are fewer visible lines and voids in the sample containing 1 and $2 \mathrm{wt} \% \mathrm{IF}-\mathrm{WS}_{2}$, and the layers seem to have merged more effectively which can be ascribed to better bonding of layers due to lower viscosity and possibly higher thermal conductivity in these samples. Hence, it is believed that the print quality generally improves with addition of IF-WS 2 nanoparticles.
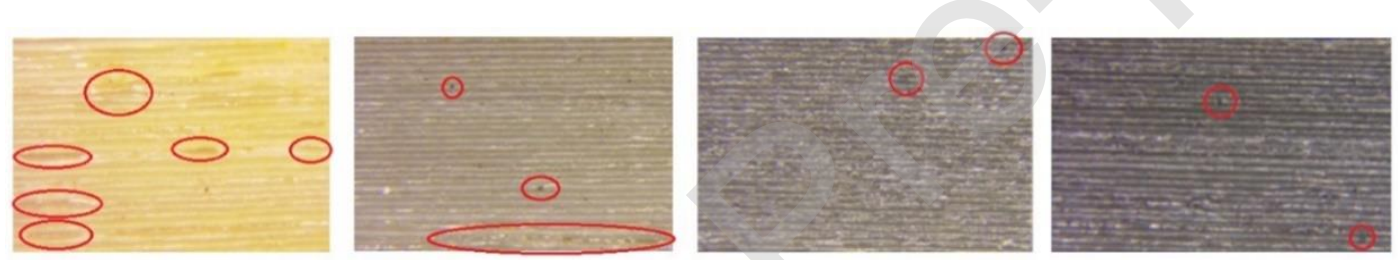

Figure 11 print quality of PEEK samples containing $0,0.5,1$ and $2 \mathrm{wt} \%$ IF-WS 2 from left to right, respectively.

\section{Conclusion}

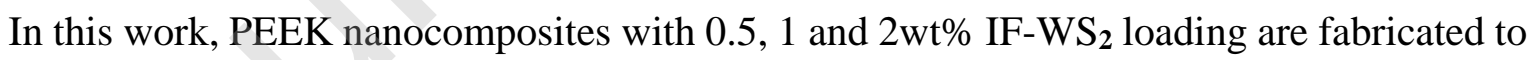
suit additive manufacturing of high-performance material by combining the useful characteristics of both organic and inorganic material. The good dispersion of IF-WS 2 nanoparticle inside the PEEK matrix (observable in the SEM images) through melt blending using a twin-screw extruder is mainly ascribed to the low tendency of IF-WS 2 nanoparticles for agglomeration, good filler-polymer interaction and the lubricating effect of these nanoparticles as indicated by a reduction in wear and friction of PEEK/IF-WS $\mathrm{W}_{\mathbf{2}}$ nanocomposites 
compares to pure PEEK. TGA thermograms showed a substantial increase in PEEK degradation temperatures due to the incorporation of IF-WS 2 . Also, the DSC results indicated an increase in PEEK crystallization upon addition of IF-WS 2 nanoparticles with a maximum crystallinity of $44 \%$ achieved in the sample containing $1 \mathrm{wt} \%$ IF- $\mathrm{WS}_{2}$ due to better dispersion of nanoparticles in this sample. It was shown that incorporation of $1 \mathrm{wt} \%$ and $2 \mathrm{wt} \%$ IF-WS can reduce the melt viscosity and improve print quality as demonstrated by microscopy images. The mechanical properties of the solid $\left(E^{\prime}\right)$ were also improved due to the reinforcing effect of IF-WS 2 as well as increased crystallinity for injection moulded and printed samples. The higher mechanical properties of injection moulded samples compared to FFF printed samples was attributed to better dispersion, higher crystallinity and enhanced packing of polymer chains in these samples. Hence, it can be concluded that incorporation of IF-WS2 into PEEK can facilitate the FFF processing of PEEK through improved melt rheology, while enhancing its final mechanical and thermal properties. Details of FFF parameter optimisation and final properties of IF-WS $2 /$ PEEK nanocomposites will be reported in a subsequent paper.

\section{Acknowledgements}

The authors wish to thank the EPSRC for funding for this research under grant reference EP/N034783/1 Novel high performance polymeric composite materials for additive manufacturing of multifunctional components.

We also wish to thank Professors Yanqui Zhu and Dr Bahareh Yazdani of the University of Exeter for providing the IF-WS2 nanoparticles. 


\section{REFERENCES}

1. Brenken B, Barocio E, Favaloro A, Kunc V, Pipes RB. Fused filament fabrication of fiberreinforced polymers: A review. Additive Manufacturing. 2018;21:1-16.

2. Arif M, Kumar S, Varadarajan K, Cantwell W. Performance of biocompatible PEEK processed by fused deposition additive manufacturing. Mater Des. 2018;146:249-259.

3. Berretta S, Davies R, Shyng Y, Wang Y, Ghita O. Fused deposition modelling of high temperature polymers: Exploring CNT PEEK composites. Polym Test. 2017;63:251-262.

4. Gonçalves J, Lima P, Krause B, et al. Electrically conductive polyetheretherketone nanocomposite filaments: From production to fused deposition modeling. Polymers. 2018;10(8):925.

5. Aho J, Bøtker JP, Genina N, Edinger M, Arnfast L, Rantanen J. Roadmap to 3D-printed oral pharmaceutical dosage forms: Feedstock filament properties and characterization for fused deposition modeling. J Pharm Sci. 2019;108(1):26-35.

6. Zhao F, Li D, Jin Z. Preliminary investigation of poly-ether-ether-ketone based on fused deposition modeling for medical applications. Materials. 2018;11(2):288.

7. Nguyen NA, Bowland CC, Naskar AK. A general method to improve 3D-printability and inter-layer adhesion in lignin-based composites. Applied Materials Today. 2018;12:138-152.

8. Forster AM, Forster AM. Materials testing standards for additive manufacturing of polymer materials: State of the art and standards applicability. US Department of Commerce, National Institute of Standards and Technology; 2015. 
9. Khaliq MH, Gomes R, Fernandes C, Nóbrega J, Carneiro OS, Ferrás LL. On the use of high viscosity polymers in the fused filament fabrication process. Rapid Prototyping Journal. 2017;23(4):727-735.

10. Wang N, Yang Z, Wang Y, et al. Interface and properties of inorganic fullerene tungsten sulphide nanoparticle reinforced poly (ether ether ketone) nanocomposites. Results in physics. $2017 ; 7: 2417-2424$.

11. de Leon AC, Chen Q, Palaganas NB, Palaganas JO, Manapat J, Advincula RC. High performance polymer nanocomposites for additive manufacturing applications. React Funct Polym. 2016;103:141-155.

12. Rinaldi M, Ghidini T, Cecchini F, Brandao A, Nanni F. Additive layer manufacturing of poly (ether ether ketone) via FDM. Composites Part B: Engineering. 2018;145:162-172.

13. Cicala G, Latteri A, Del Curto B, Lo Russo A, Recca G, Farè S. Engineering thermoplastics for additive manufacturing: A critical perspective with experimental evidence to support functional applications. Journal of applied biomaterials \& functional materials. 2017;15(1):10-18.

14. Râpă M, DARIE-NIŢĂ R, Grosu E, et al. Effect of plasticizers on melt processability and properties of PHB. Journal of Optoelectronics and Advanced Materials. 2015;17(11-12):17781784.

15. Merz E, Nielsen L, Buchdahl R. Influence of molecular weight on the properties of polystyrene. Industrial \& Engineering Chemistry. 1951;43(6):1396-1401. 
16. Simić D, Stojanović DB, Kojović A, et al. Inorganic fullerene-like IF-WS2/PVB nanocomposites of improved thermo-mechanical and tribological properties. Mater Chem Phys. 2016;184:335-344.

17. Yang H, Liu S, Li J, Li M, Peng G, Zou G. Synthesis of inorganic fullerene-like WS2 nanoparticles and their lubricating performance. Nanotechnology. 2006;17(5):1512.

18. Hou X, Shan C, Choy K. Microstructures and tribological properties of PEEK-based nanocomposite coatings incorporating inorganic fullerene-like nanoparticles. Surface and Coatings Technology. 2008;202(11):2287-2291.

19. Naffakh M, Díez-Pascual AM, Marco C, Gómez MA, Jiménez I. Novel melt-processable poly (ether ether ketone)(PEEK)/inorganic fullerene-like WS2 nanoparticles for critical applications. The Journal of Physical Chemistry B. 2010;114(35):11444-11453.

20. Díez-Pascual AM, Naffakh M, Marco C, Ellis G, Gómez-Fatou MA. High-performance nanocomposites based on polyetherketones. Progress in Materials Science. 2012;57(7):11061190.

21. Díez-Pascual AM, Naffakh M, Marco C, Ellis G. Rheological and tribological properties of carbon nanotube/thermoplastic nanocomposites incorporating inorganic fullerene-like WS2 nanoparticles. The Journal of Physical Chemistry B. 2012;116(27):7959-7969.

22. Naffakh M, Díez-Pascual AM. Thermoplastic polymer nanocomposites based on inorganic fullerene-like nanoparticles and inorganic nanotubes. Inorganics. 2014;2(2):291-312.

23. Li L, Sun Q, Bellehumeur C, Gu P. Investigation of bond formation in FDM process. Solid Freeform Fabrication Proceedings,(403). 2002;400407. 
24. Tardif X, Pignon B, Boyard N, et al. Experimental study of crystallization of PolyEtherEtherKetone (PEEK) over a large temperature range using a nano-calorimeter. Polym Test. 2014;36:10-19.

25. Sampaio M, Buciumeanu M, Henriques B, Silva FS, Souza J, Gomes J. Comparison between PEEK and Ti6Al4V concerning micro-scale abrasion wear on dental applications. journal of the mechanical behavior of biomedical materials. 2016;60:212-219.

26. Fayose F, Huan Z. Energy consumption and efficiency in single screw extrusion processing of selected starchy crops. 2015;30(3):375 - 392.

27. Williams J. Particle toughening of polymers by plastic void growth. Composites Sci Technol. 2010;70(6):885-891.

28. Díez-Pascual AM, Naffakh M, Gómez-Fatou MA. Mechanical and electrical properties of novel poly (ether ether ketone)/carbon nanotube/inorganic fullerene-like WS2 hybrid nanocomposites: Experimental measurements and theoretical predictions. Mater Chem Phys. 2011;130(1-2):126-133.

29. Zhang M, Guo B, Xu J. A review on polymer crystallization theories. Crystals. 2016;7(1):4.

30. Righetti M. Crystallization of polymers investigated by temperature-modulated DSC. Materials. 2017;10(4):442.

31. Ratoi M, Niste VB, Walker J, Zekonyte J. Mechanism of action of WS 2 lubricant nanoadditives in high-pressure contacts. Tribology letters. 2013;52(1):81-91.

32. Peyser P, Bascom WD. Effect of filler and cooling rate on the glass transition of polymers. Journal of Macromolecular Science, Part B: Physics. 1977;13(4):597-610. 
33. Rajesh J, Soulestin J, Lacrampe M, Krawczak P. Effect of injection molding parameters on nanofillers dispersion in masterbatch based PP-clay nanocomposites. EXPRESS polymer Letters. 2012;6(3):237-248. 


\section{Figure Captions}

Figure 1 Screw design used for processing of PEEK/IF-WS ${ }_{2}$ filaments

Figure 2 Specific Mechanical Energy (SME) for compounding of PEEK and IFWS $2 /$ PEEK nanocomposites

Figure 3 SEM images of PEEK nanocomposites containing a) $0.5 \mathrm{wt} \%$, b) $1 \mathrm{wt} \%$ c) $2 \mathrm{wt} \%$ IFWS2, d) EDX mapping and e) EDX analysis of sample containing 0.5wt $\%$ IF-WS 2

Figure 4 Impact strength of PEEK samples containing various amounts of IF-WS 2

Figure 5 Variation of sample weight with temperature for PEEK samples with $0,0.5,1$ and $2 \mathrm{wt} \% \mathrm{IF}-\mathrm{WS}_{2}$

Figure 6 a) changes in crystallinity (\%) and b) crystallization temperature vs IF-WS 2 content Figure 7 a) Static and dynamic coefficient of friction and b) wear rate for PEEK samples containing different loadings of IF-WS 2

Figure 8 shear viscosity versus shear rate for PEEK samples containing different amounts of IF-WS 2

Figure 9 Storage modulus $\left(\mathrm{E}^{\prime}\right)$ and Loss tangent $(\tan \delta)$ vs temperature for injection moulded PEEK samples

Figure 10 Storage modulus $\left(E^{\prime}\right)$ and Loss tangent $(\tan \delta)$ vs temperature for printed PEEK samples

Figure 11 print quality of PEEK samples containing $0,0.5,1$ and $2 \mathrm{wt} \%$ IF-WS 2 from left to right, respectively. 


\section{Table Captions}

Table 1 Comparison between E' and Tg of injection moulded and 3D printed PEEK samples 